\title{
SYNERGISM IN CONDITIONS EVALUATION TECHNOLOGIES: THE EXAMPLE OF THE SAN JUAN FORTIFICATION WALLS
}

\author{
J. FEINBERG ${ }^{1}$, D. WOODHAM ${ }^{2} \&$ C. CITTO $^{2}$ \\ ${ }^{1}$ The Collaborative, Inc., USA. \\ ${ }^{2}$ Atkinson-Noland \& Associates, USA.
}

\begin{abstract}
The original construction of the San Juan fortification walls in Puerto Rico dates from the mid-16th century. The fortifications were constructed with the single purpose of defending the City of San Juan and its harbour from attack, principally by sea. Over a four-century period of construction and reconstruction, the fortification walls evolved from one construction typology into at least ten identifiable types. The walls investigated in this study are $750 \mathrm{~m}$ long and $15 \mathrm{~m}$ high, and include two bastions and the San Juan Gate. The challenging task of evaluating such complex structures required the synergism between historic research and modern diagnostic techniques to develop a deep understanding of the history, materials and structural behaviour of the fortification walls. In addition to historic research, 21st-century technologies selected to evaluate the walls included laser scans, digital photo-documentation, wall coring, remote visual inspection of the core interior, microwave radar scans, thermography, characterization of stone and mortar types and strength, and finite element modelling. Keywords: finite element modelling, historic, masonry, non-destructive, radar, wall.
\end{abstract}

\section{INTRODUCTION}

Logical thinking can create theories for causes of deterioration in historic building materials and constructions. It can also create pathways to research. The 'why' of deterioration often has a complex answer as deterioration is the result of multiple complex forces, decisions and practice - the who, the what, the when and the how.

The United States National Park Service, as the stewards of the UNESCO World Heritage Site of Old San Juan, Puerto Rico, wanted the answers to why a significant portion of the fortifications were deteriorating and what interventions might be recommended to achieve stabilization. The walls have a remarkable historical background and were constructed by the Spanish Crown to protect the large harbour and beyond from foreign invasion. Occupying a point of land on the north side of the harbour, the walls and two fortresses surrounded the city until 1897 when the wall was partially opened due to overcrowding within its confines. Not long after Ponce de León established the San Juan settlement, the harbour was recognized as a key stopping point for Spanish treasure galleons on their journey from South America back to Spain. Spain was not the only European power to recognize the importance of the harbour at San Juan, as invasion attempts by the English and the Dutch bear witness. Because the primary fortifications at the harbour mouth were deemed to be too strong for invasive landings, attacks were largely repulsed by the local troops and people manning outlying defensive outposts. Typical of the Caribbean climate, disease also played its part in repulsing invasions as the invading troops became ill. Only once in the earliest years were the invaders successful, burning the then small settlement.

This paper is part of the proceedings of the 3rd International Conference on Defence Sites: Heritage and Future (Defence Heritage 2016)

www.witconferences.com 
As the political alliances in Europe changed over time, Spain's awareness and concern for the safety of the harbour from its enemies also rose and fell. Major improvements to the fortifications occurred under the direction of its Irish-born military engineers primarily during the last quarter of the 18th century, with significant improvements to the fortresses and fortification walls. Typical of coastal fortifications, their period of usefulness faded in direct proportion to improvements in ship-based armaments with their increased power and range. In addition, the advent of steam-powered warships allowed the positioning of the ships with little regard to currents, tides and wind direction. By the time of the US invasion at the end of the 19th century, the number of armaments had been significantly reduced to less than $10 \%$ of its original.

The National Park Service maintains the walls and fortresses for the enjoyment of people from all over the world, and this project has the underlying intent to continue their preservation by understanding the complex forces of deterioration and providing appropriate interventions.

\section{RESOURCE DESCRIPTION}

The fortifications are a part of the walled city of Old San Juan, Puerto Rico. There are multiple scarps and two bastions, constructed from calcareous sandstone from 1538 until the early 1800 s with significant repair and replacement campaigns in the 20th century, in part a response to collapses. The length of the walls investigated in this study is $800 \mathrm{~m}$, height ranges from $5.5 \mathrm{~m}$ to $14 \mathrm{~m}$ and the wall thickness at its base is $3.0-3.7 \mathrm{~m}$ (Fig. 1).

The walls investigated in this study are the south and west portions of the fortifications and are part of the overall system anchored by the Castillo San Felipe del Morro at the seaward end of the peninsula, and Castillo de San Cristobal anchoring the opposite end at the isthmus to the mainland. The fortresses were designed to protect the harbour entrance and the land approach to the city. The improvements made to the walls circa 1770 to circa 1803 changed the plan view configuration from following the cliff face in a series of short walls to long straight walls to assist in line-of-sight firing. Unfortunately, the change meant the walls were not fully founded on bedrock; some sections were now founded on sand. The base of the

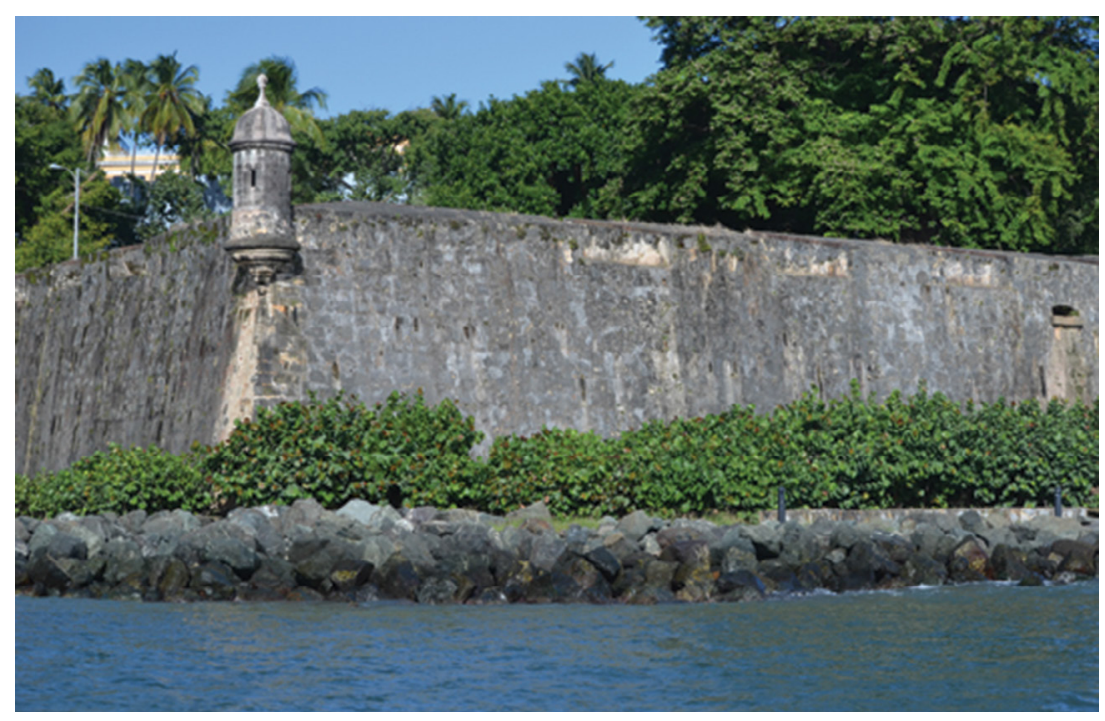

Figure 1: View of San Agustin Bastion from the sea. 
walls became more fully exposed to wave action. Puerto Rico waters are not always gentle as the island is subjected to major hurricanes; the land is also not always calm, with the occurrence of major earthquakes.

\section{HISTORIC RESEARCH PROCESS}

Major research had been carried out in the 1980s on the history of the fortifications [1], with the most effort centred on the history of the two fortresses. This previous research was based on material found in various Spanish archives and in the National Archives from the US Army. Our research divided the history into four periods: the early Spanish period of initial construction from the early 1500s until 1770; the period from 1770 until 1898, the period of Spanish reconstruction and improvements; and the period from 1898 to circa 1960, during which the US Army made significant alterations in terms of additional buildings but reactive responses to fortification wall condition issues. After the US Army period is the National Park Service period that continues to date. The focus of the Park Service has included removal of the buildings constructed after the Period of Significance and interpretation and preservation of the resources. In 1983 the park was recognized as a World Heritage Site [2].

\section{Statement of Significance}

The main elements of the massive fortification of San Juan are La Fortaleza, the three forts of San Felipe del Morro, San Cristóbal and San Juan de la Cruz (El Cañuelo), and a large portion of the City Wall, built between the 16th and 19th centuries to protect the city and the Bay of San Juan. They are characteristic examples of the historic methods of construction used in military architecture over this period, which adapted European designs and techniques to the special conditions of the Caribbean port cities. La Fortaleza (founded in the early 16th century and considerably remodeled in later centuries) reflects developments in military architecture during its service over the centuries as a fortress, an arsenal, a prison, and residence of the Governor-General and today the Governor of Puerto Rico.

Criterion (vi): La Fortaleza and San Juan National Historic Site outstandingly illustrate the adaptation to the Caribbean context of European developments in military architecture from the 16th to 20th centuries. They represent the continuity of more than four centuries of architectural, engineering, military, and political history.

Our research focus was on the specific history of our section of walls and on the general history of the wider aspects of wall construction, stone materials, the mortar components, the construction labour and the military engineers who designed the fortifications in each of the various periods. One important and continuous factor familiar to people in the field became apparent: regardless of period, there was a critical imbalance between the funds requested by site administrators for repairs and the money made available. Repairable situations most often led to collapsed wall sections. Of course, the cost of reconstruction far exceeded the earlier requested funds for repair.

The lack of proper funding also affected the initial construction. Typically the walls were faced with well-executed ashlar stone masonry, of some 18-21 in. in depth (0.5 m), laid over very rough masonry referred to as mamposteria. This technique, used in Puerto Rico and in 


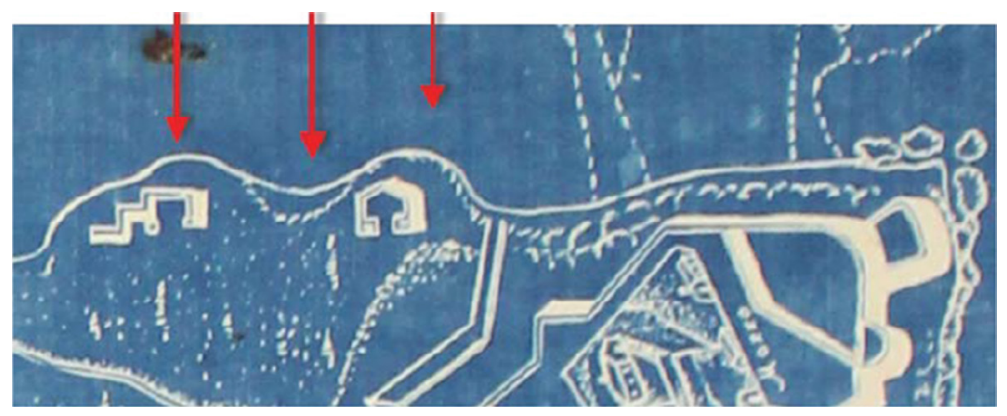

Figure 2: Section of a 1678 map of San Juan showing a version of Santa Elena Bastion.

the Spanish-controlled Philippine territory, placed stones and mortar into forms. The result was a weak masonry. The mortar appears to have had more clay than lime and sand as field investigation revealed little to no mortar in the 9-foot-deep cores of the wall, leading to the belief that the mortar, what little there was, had washed away. The choice of masonry construction techniques was likely to have been influenced by the lack of skilled masons and workforce being too small in numbers, racked by disease and with low motivation given the lack of payment of wages for one or more years.

Particularly valuable in the historic research were the historic plans that in particular indicated the evolution in the alignment of the walls, progressing from following the cliff faces to straight scarps (Fig. 2). The condition analysis and construction plans of the 20th century clearly showed the evolution in conditions ending in the collapse of multiple wall sections (Fig. 3). The resulting reconstructions were without much historic integrity, with several sections faced with stone veneer over an underlying new concrete wall. The research revealed multiple wall typologies: three basic ones each with various iterations, and significant findings. The results of the field evaluation revealed even more information, confirming information from the historic research.

\section{FIELD SURVEY AND DOCUMENTATION}

Three techniques were used: laser scanning, high-resolution photography and infrared thermography. The laser scans were successfully manipulated to test whether topographic analysis of the wall faces would reveal surface anomalies, larger areas of out-of-plane
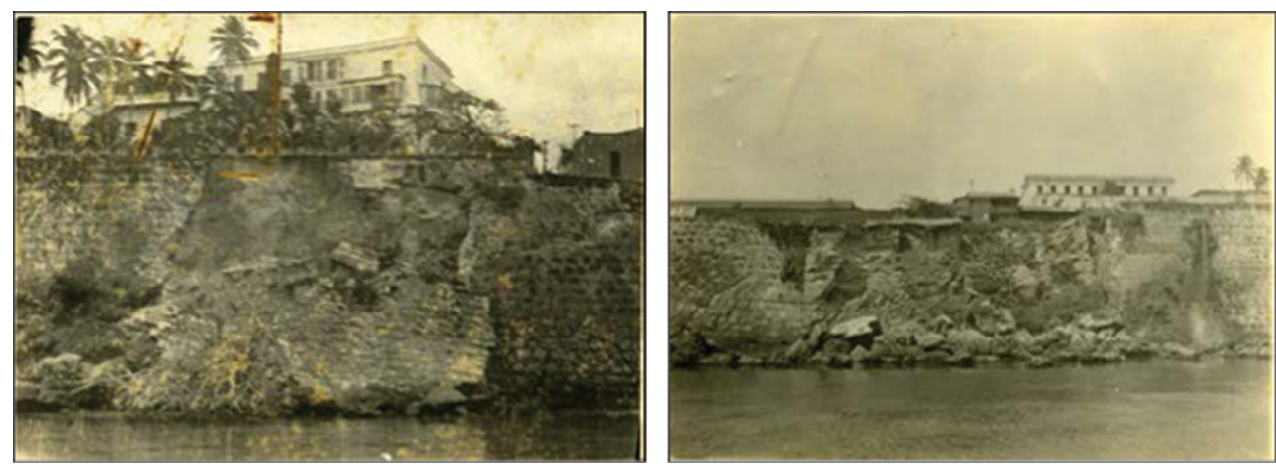

Figure 3: Historic photos documenting past collapses of wall sections of Casa Blanca Scarp circa 1922, at left, and of El Polvorín Scarp circa 1922, at right. 


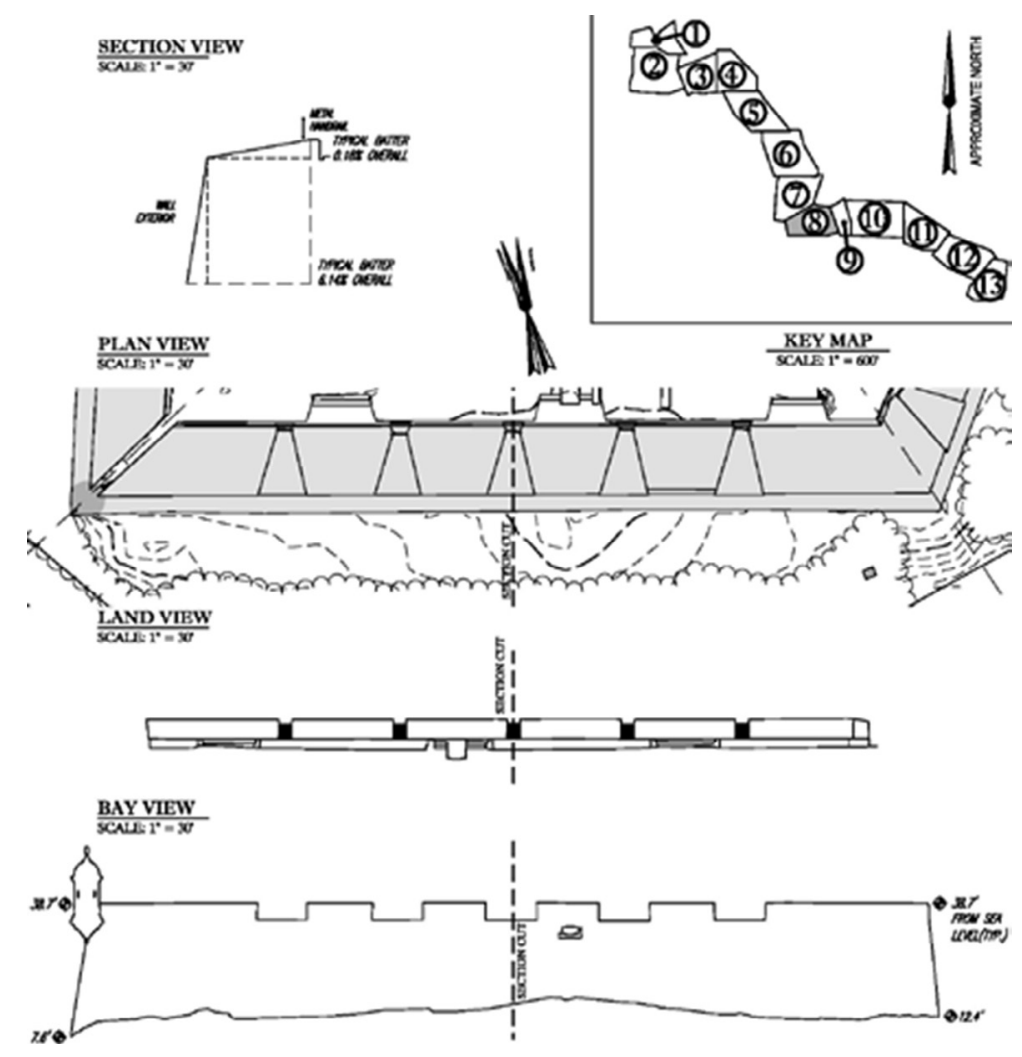

Figure 4: Wall survey for San Agustin Bastion.

anomalies and movement adjacent to cracks. This test was in addition to the laser scan used for computer-aided design drawings (Fig. 4). The thermographic images were taken at the same time as the high-resolution digital photography, both from a boat. The photography covered large sections of wall and detailed subsections of the larger scale images. Cooler areas seen in the thermographic images could be compared with the photographs of the same area to assist in determining if the temperature difference was attributable to through-wall water seepage or apparent vegetative growth (Fig. 5). These images were taken after an extended period of above-average rainfall. Correlation of the locations of areas of seepage with areas later revealed by ground-penetrating radar (GPR) as having above-average voids in the masonry at depth confirmed the water source to be largely groundwater.

\section{FIELD RESEARCH}

The field research techniques were selected to provide comprehensive information about the conditions of the walls and the likely causes of deterioration. In addition to laser scanning, infrared thermographic imaging and high-resolution digital photography, other techniques included the use of GPR with significant coverage of the historic wall sections, the drilling of eight horizontal cores from the wall face to an average 9-foot depth, which served to assist in the calibration of the GPR readings and provided materials for strength testing of stone removed by the cores and some mortar for laboratory analysis. The cores were viewed with a 

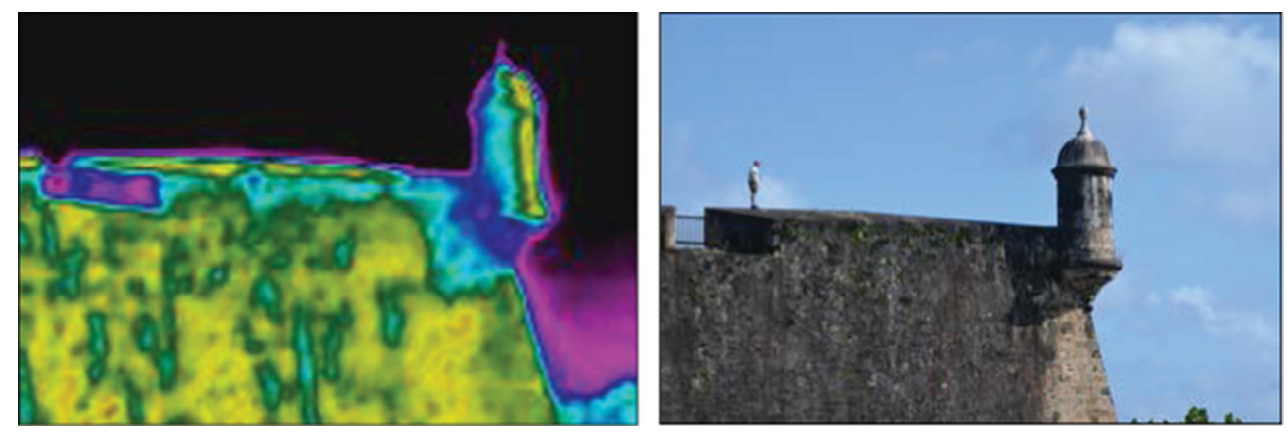

Figure 5: Thermal (left) image and visible light (right) of Santa Elena Bastion. The bluegreen areas in the thermal image show areas with dampness in the masonry.

borescope with colour video recording, clearly indicating the subsurface conditions including the significant lack of mortar and prevalence of voids (Fig. 6).

Sampling of mortar at the surface was taken from the oldest sections of the walls. Samples were also taken of biological growth for its characterization in the laboratory; of particular concern were the blue-green algae. Samples of woody plants, ferns and similar vegetative growth were also taken.

Visual review of the wall conditions occurred multiple times during the fieldwork; from the initial day's visual investigation each new group of information was reviewed and the walls now viewed with new insight. The reviews included documentation of stone masonry problems such as cracks and material condition problems: lost material, eroded material and eight other issue areas including efflorescence. Particular attention was given to the drainage systems and natural surface flows above and behind the walls. Were the flows observed as seepage percolating down from behind the parapets and merlons or was the water coming from between the sandstone strata that we knew was interbedded with sands and clays? The question was asked of ourselves and we recognized that the answer would most likely come from the next phase of field research and monitoring.
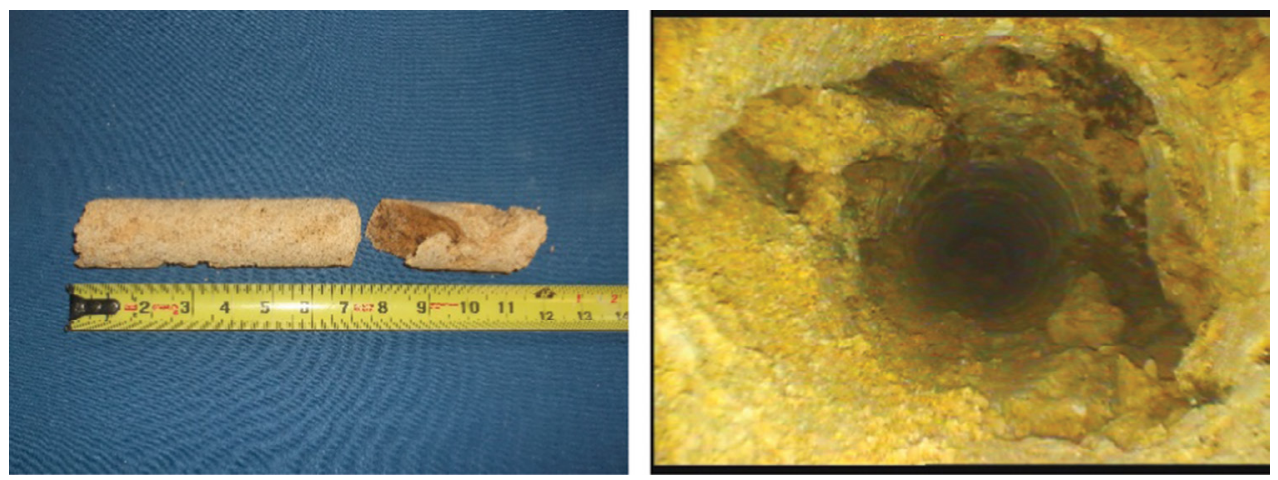

Figure 6: Comparison between a segment of wall section retrieved by deep coring at a depth of $0.55-0.85 \mathrm{~m}$ (left) and a videoscopic image of the interior of the core hole (right). 


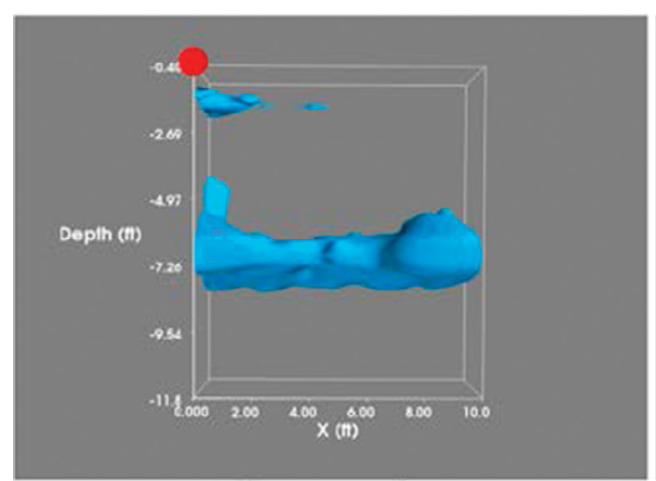

Bottom view

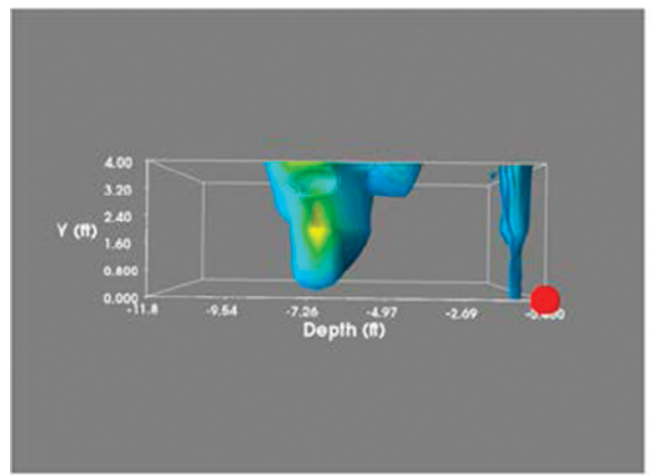

Lateral (left) view

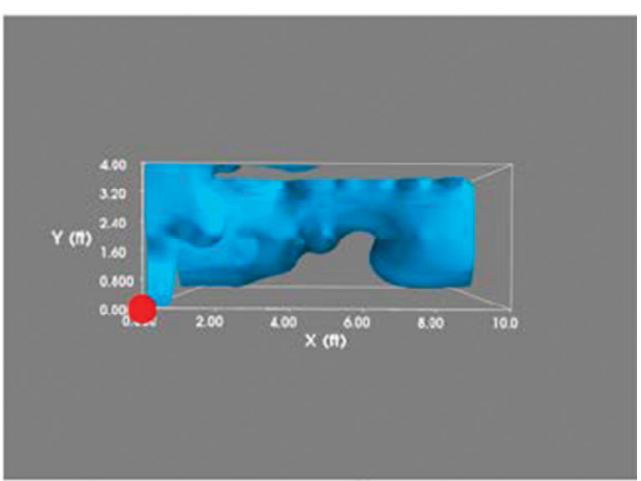

Front view

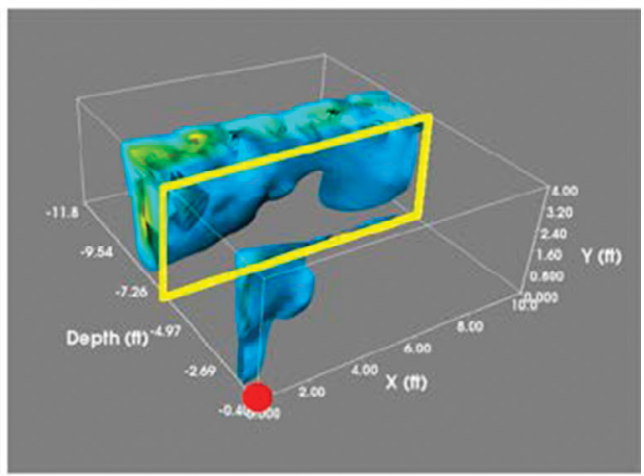

Isometric view

Figure 7: Three-dimensional rendering images based on GPR data showing the most likely extent and distribution of internal voids. Estimated wall thickness at this location is $2.0 \mathrm{~m}(6.5 \mathrm{ft})$. Large voids at the back of the wall, extending to the soil, are visible. Yellow frame in image at lower right indicates approximate location of the back of the wall.

\section{LABORATORY ANALYSIS}

In addition to the analysis of the biological growth and the core stone material testing, the mortars were tested by the Middendorf method [3] to assess the presence of all components including Portland cement. From historic research we knew that the Spanish engineers used Portland cement in the late 1890s. The GPR data were evaluated and the relative amount of voids determined for the walls, and one area that had been scanned on a 2-foot or $60 \mathrm{~cm}$ spaced grid was evaluated and displayed as a three-dimensional model (Fig. 7). The GPR, along with the cores and the historic research, provided data used to develop the wall sections.

\section{MODELLING}

Using computer modelling [4], representative wall sections of the original wall construction were assessed as to how they would stand up to earthquakes. The fortification walls are located in a region that is seismically active and several major earthquakes have been recorded in the past. The earthquake intensity used in the analysis has a $2 \%$ probability of being exceeded in 50 years or, in other terms, a return period of 2,500 years [5]. 
The complexity of the fortification walls required an advanced nonlinear analysis to determine whether the expected seismic forces would damage the walls. A response spectrum was generated considering the seismicity of the region. The spectrum was used in the computer model to generate equivalent static lateral forces likely to be experienced by the walls during an earthquake. Lateral earth pressures were also included in the model under the assumption that the walls would retain soil. In this analysis, the fortification walls were modelled in a way that cracks would form in the structure once the material strength is exceeded. Material properties used in the finite element analysis were adjusted to account for the reduced strengths due to the saturated condition of the walls. The calcareous sandstone that makes up the expected majority of the stone in the wall was found to be very porous. The strength of the porous sandstone tends to decrease with the water content.

The seismic capacity of the walls was evaluated based on a static pushover analysis, where the lateral reaction at the base of the wall (base shear) is plotted against the lateral displacement measured at the top of the wall. In this approach, the seismic forces are applied to the structure incrementally, and the force and displacement values are recorded at each step. If the base shear is plotted as a percentage of the total seismic forces (seismic demand), a capacity curve is produced. The capacity curve simply summarizes the amount of seismic force the wall is able to carry. If the wall is not able to resist $100 \%$ of the seismic demand, the wall is deemed deficient. Results from the seismic evaluation indicate that the original walls do not have the capacity to carry the required seismic demand, suggesting that the walls could suffer substantial damage under a strong earthquake with a very long return period.

\section{FIRST-PHASE RESULTS}

From a process standpoint, the use of the selected diagnostic techniques coupled with the historic research was quite successful. For example, the weakness of the walls was found by the diagnostic techniques; the history relative to the quality of the labour, the scarcity of the materials for higher quality mortar, the lack of adequate funding for short-term completion of construction and for maintenance, and the military engineers' desire for straight walls without adequate regard for bearing conditions provided an understanding of the why of the weakness. The use of mamposteria as a construction technique was a logical response to the lack of qualified masons and lime for competent mortars.

The pathways for research came initially from past experience with similar fortifications and the typical associated problems of shoreline-located walls. These pathways for research were expanded by the historic research, with choices made as to direction and intensity of effort. This evolution is typical for any investigator, for example the back of wall drainage issue is of concern for any retaining wall. The extent of the problem was revealed by the mapping of vegetation by digital imaging and the use of thermographic imaging. The pattern of seepage locations and relative amounts indicated the problem's extent and intensity. The historic research revealed the lack of maintenance by the US Army of the extensive drainage system constructed by the Spanish Military, a substitution of the earlier system by a less effective system and inadvertent changes by the National Park Service that changed drainage patterns by removing roads that had interrupted and directed flows to structured drains.

The source of subsurface water was evaluated based on historic research into multiple 20th-century projects for which geologic borings had been completed, indicating the interbedded layers of sandstone, clay and sand. A contractor in 1938 rejected the possibility of founding a reconstructed wall portion on the weak stone, based on information found in his field reports and requests for compensation for the added cost for reinforcement. Again, this 
Table 1: Synergism matrix for employed techniques.

\begin{tabular}{|c|c|c|c|c|c|c|c|}
\hline & Core & $\begin{array}{l}\text { Video } \\
\text { scope }\end{array}$ & $\begin{array}{l}\text { Laser } \\
\text { survey }\end{array}$ & $\begin{array}{l}\text { Infrared } \\
\text { thermal }\end{array}$ & Radar & Biology & $\begin{array}{l}\text { Finite element } \\
\text { analysis }\end{array}$ \\
\hline $\begin{array}{l}\text { Video } \\
\text { scope }\end{array}$ & ++ & & & & & & \\
\hline $\begin{array}{l}\text { Laser } \\
\text { survey }\end{array}$ & & & & & Syn & metry & \\
\hline $\begin{array}{l}\text { Infrared } \\
\text { thermal }\end{array}$ & + & ++ & + & & & & \\
\hline Radar & +++ & ++ & + & + & & & \\
\hline Biology & & & + & +++ & + & & \\
\hline $\begin{array}{l}\text { Finite } \\
\text { element } \\
\text { analysis }\end{array}$ & ++ & ++ & ++ & & ++ & & \\
\hline $\begin{array}{l}\text { History } \\
\text { research }\end{array}$ & +++ & ++ & & + & +++ & + & + \\
\hline
\end{tabular}

path of research was based on logic; confirmation came in the laboratory on stone samples from the interior of the wall, the stone having been originally sourced from the same relatively weak bedrock.

As intended, many of the diagnostic techniques were able to be calibrated by other techniques. Many diagnostic techniques provided a different and confirming perspective on the condition issues (Table 1). Further, many of the techniques confirmed expectations provided by the historic research and provided logical pathways for other historic research to provide more answers and more confirmation on the why of deterioration.

As expected, this first phase informed the decision of what additional research was required.

\section{FURTHER STUDY AND PHASE TWO SCOPE}

Further study was required to determine several underlying conditions with likely contribution to long-term problems. From the historic research, we knew that many caverns had formed at the base of several wall sections during the period 1925-1951. As one of the recommended wall strengthening techniques to be evaluated was the injection of voids with specially formulated grout, there was an expressed concern that we needed to avoid pumping the grout into the ocean via a cavern and none of us wanted the wall section to be founded on a cavern. The tasks of this phase therefore included detailed GPR evaluation of the base of those sections of walls with higher than average percentages of voids, using the previously tested $60 \mathrm{~cm}$ by $60 \mathrm{~cm}$ grid pattern from which three-dimensional images of the select areas of greatest concern could be created. To develop information about drainage at depth, groundwater levels, interconnection between the ocean and areas under the walls and bastions, a series of seven vertical bores were completed and equipped with piezometers. Stone bedrock samples were taken during the boring operation to provide knowledge about strata thicknesses and interbedding material in general, and to assess the competency of the bedrock for the installation of rock anchors to assist in earthquake wall resistance. Five crack monitors 
were installed that, with the data from the piezometers and the weather station, would allow us to see how the wall reacted when the ground was saturated with moisture and backside of wall pressures was greatest, and how the wall reacted to diurnal temperature change. The database was further enhanced by the import of tide information. The monitoring system was installed in the summer of 2015 and not all conditions have been encountered to provide all of the expected data. For example, the area has experienced a significant drought.

\section{INTERPRETATION OF THE DATA, PARTIAL RESULTS FROM PHASE TWO}

The bedrock was of quite low strength and is unlikely to be effectively used for the placement of rock anchors. The crack monitors indicate diurnal movement, indicating the need to maintain some cracks rather than have them filled. Much of the mortar in the wall faces having been found to have very high Portland cement content - not original but placed in the 20th century - it cannot serve to absorb movement. The piezometers as a benefit of the drought clearly show a relationship to the tide levels. If it were a direct relationship, the response would be in time with the tides indicating direct connectivity. There is a two- to two-and-ahalf-hour delay, indicating possible charging of the bedrock and interbedded sand and clay strata by tidewater pushing up the overlying freshwater.

\section{CONCLUSIONS}

The historic research, conducted as part of this project, informed the field investigations, laboratory analysis and our recommendations for further actions. Conversely, the investigative techniques employed could be used to confirm documented previous construction and interventions. As intended, many of the diagnostic techniques were able to be calibrated by other techniques and allowed for extrapolation of the non-destructive techniques to additional areas of investigation.

\section{REFERENCES}

[1] Bearss, Edwin C., Historic Structure Report - Historic Data Section. San Juan Fortifications, 1898-1958, San Juan National Historic Site, Puerto Rico. U.S. Department of the Interior/National Park Service, February 1984. Document no. D2185, as an example of a source document for historic research.

[2] UNESCO World Heritage Center, World Heritage List, La Fortaleza and San Juan National Historic Site in Puerto Rico, Statement of Significance, available at http:// whc.unesco.org/pg.cfm?cid=31\&id_site=266_(accessed 15 January 2016).

[3] B. Middendorf et al., Chemical Characterization of Historic Mortars, State-of-the-Art Report of RILEM Technical Committee 167-COM: Characterization of Old Mortars with Respect to their Repair. RILEM Publications SARL, 2004.

[4] Midas FEA 2016. Nonlinear and detail FE Analysis System for Civil Structures, v1.1. Midas Information Technology Co. Ltd.

[5] American Society of Civil Engineers (ASCE), Seismic Rehabilitation of Existing Buildings (ASCE/SEI 41-06), Reston, Virginia, 2007. 